\title{
Neonatal Screening: Identification of Children with $11 \beta$-Hydroxylase Deficiency by Second-Tier Testing
}

\author{
Nils Janzen ${ }^{a, c, i} \quad$ Felix G. Riepe ${ }^{b}$ Michael Peter ${ }^{c}$ Stefanie Sander ${ }^{c}$ \\ Ulrike Steuerwald $^{c}$ Eckhard Korsch ${ }^{d}$ Friedrich Krulle Hermann L. Müller ${ }^{f}$ \\ Sabine Heger ${ }^{g}$ Christoph Brack ${ }^{\text {h Johannes Sander }}{ }^{c}$ \\ aDepartment of Neuropediatrics, Children's Hospital, Ruhr University of Bochum, Bochum, b Department of \\ Paediatrics, University of Kiel, Kiel, ' CScreening Laboratory Hannover, Hannover, ${ }^{d}$ Clinic for Paediatric Diseases, \\ Kliniken der Stadt Köln gGmbH, Köln, ${ }^{e}$ Clinic for Paediatric Diseases, Ostfriesisches Krankenhaus, Klinik Aurich, \\ Aurich, ${ }^{\mathrm{f} C l i n i c}$ for Paediatric Diseases, Klinikum Oldenburg, Oldenburg, ${ }^{9} \mathrm{Clinic}$ for Paediatric Diseases,

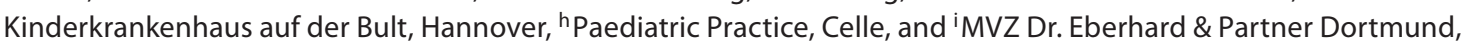 \\ Dortmund, Germany
}

\section{Key Words}

$11 \beta$-Hydroxylase deficiency $\cdot$ Congenital adrenal hyperplasia $\cdot$ Steroid profiling $\cdot$ Newborn screening

\begin{abstract}
Background: 21-Hydroxylase deficiency (21-OHD) is the target disease of newborn screening for congenital adrenal hyperplasia (CAH). We describe the additional detection of patients suffering from 11ß-hydroxylase deficiency (11-OHD) by second-tier testing. Method: Over a period of 5 years, screening for CAH was done in a total of 986,098 newborns by time-resolved immunoassay (DELFIA ${ }^{\circledR}$ ) for $17 \alpha$-hydroxyprogesterone (17-OHP). Positive samples were subsequently analyzed in an LC-MS/MS second-tier test including 17-OHP, cortisol, 11-deoxycortisol, 4-androstenedione and 21-deoxycortisol. Results: In addition to 78 cases of 21-OHD, 5 patients with 11-OHD were identified. Diagnostic parameters were a markedly elevated concentration of 11-deoxycortisol in the presence of a low level of cortisol. Androstenedione was also increased. In contrast to 21-OHD, concentrations of
\end{abstract}

21-deoxycortisol were normal. Conclusion: Steroid profiling in newborn blood samples showing positive results in immunoassays for 17-OHP allows for differentiating 21-OHD from 11-OHD. This procedure may not detect all cases of 11$\mathrm{OHD}$ in the newborn population because there may be samples of affected newborns with negative results for 17-OHP in the immunoassay.

Copyright $\odot 2012$ S. Karger AG, Basel

\section{Introduction}

Newborn screening for congenital adrenal hyperplasia (CAH) due to 21-hydroxylase deficiency (21-OHD) is usually done by immunoassays. Such tests, however, produce a high number of false-positive results due to stimulation of steroid production in preterms and in stressed newborns on the one hand and due to crossreactions of the antibody with other steroids on the other hand. To avoid unnecessary stress and anxiety in families caused by false-positive results, we have been

\section{KARGER \\ Fax +4161306 1234 \\ E-Mail karger@karger.ch}

www.karger.com
(C) 2012 S. Karger AG, Basel

$1663-2818 / 12 / 0773-0195 \$ 38.00 / 0$

Accessible online at:

www.karger.com/hrp
Dr. med. Dr. rer. nat. Nils Janzen, Abteilung für Neuropädiatrie mit Sozialpädiatrie

Klinik für Kinder- und Jugendmedizin im St. Josef Hospital

Ruhr-Universität Bochum

Alexandrinenstrasse 5, DE-44791 Bochum (Germany)

Tel. +49234509 2687, E-Mail n.janzen@klinikum-bochum.de 
applying LC-MS/MS as an immediate second-tier test on the original blood spot for several years and therefore were able to reduce the false-positive rate considerably.

$11 \beta$-Hydroxylase deficiency (11-OHD) is not currently a primary target of newborn screening. We found that 11-OHD can be detected in newborns showing elevated concentrations of $17 \alpha$-hydroxyprogesterone (17-OHP) in the immunoassay. Considering the number of severe sequelae caused by 11-OHD, we recommend to include the defect into newborn screening as a routine target.

\section{Methods}

Blood collection was generally done on days 2-4. Postal transportation took up to 2 days in $63.1 \%$ and up to 4 days in $92.9 \%$. Analyses were finished on day 3 in $51 \%$ of all samples, whereas on day $5,90.2 \%$ of the results had been finalized. During the last 5 years our laboratory analyzed 986,098 first samples for CAH by time-resolved immunoassay (DELFIA ${ }^{\circledR}$ ) for 17-OHP with cut-off values adjusted for gestational age and for lot number of the test kit as described earlier $[1,2]$. In 6,359 samples $(0.64 \%$ of total) the cut-off was exceeded. In these cases the blood spots were additionally analyzed by LC-MS/MS for a steroid profile including the steroids 17-OHP, cortisol, 11-deoxycortisol, 4-androstenedione and 21-deoxycortisol. The LC-MS/MS analyses were performed as described before [3]. In short, LC separation was achieved by using an Atlantis ${ }^{\circledR} \mathrm{C} 18$ column and water-methanolformic acid gradient as a mobile phase and a flow rate of $250 \mu \mathrm{l} /$ min over a run time of $6 \mathrm{~min}$. Steroids were measured in MRM mode with electrospray interface (positive ion mode). No derivatization was needed. Quantification was done by use of external calibration as well as internal deuterated steroids. There was a linear correlation between steroid concentration and signal intensities for 17-OHP, 11-deoxycortisol, 21-deoxycortisol, and 4-androstenedione from 3-125 nmol/l, 12.5-250 nmol/l for cortisol. The coefficient of regression was $>0.998$ for all steroids. By dilution of samples showing concentrations that were well above the highest calibration standard, we were able to show that steroid concentrations that were tenfold higher than the highest calibrator still complied with linearity. Percentiles for steroid concentrations were calculated by Microsoft ${ }^{\circledR}$ Excel 2003 and MedCalc $^{\circledR}$ v11 (Mariakerke, Belgium).

\section{Genetic Analysis of the CYP11B1 Gene}

Blood for genetic analysis was drawn after informed consent of the caregivers. Genomic DNA was prepared from peripheral blood leukocytes, using a standard protocol. The mutation analysis was performed after PCR amplification by direct DNA sequencing of the complete coding region of the CYP11B1 gene, including the intron-exon boundaries as described previously [4]. The samples were analyzed on an automated sequencer. The mutations were named according to the recommendations of the Nomenclature Working Group [5]; the prefix c indicates the cDNA sequence position.
Table 1. Percentiles calculated for newborns and steroid spectra of patients with 11-OHD

\begin{tabular}{lcrrrr}
\hline & $\begin{array}{l}17 \alpha \text {-Hydroxy- } \\
\text { progesterone }\end{array}$ & $\begin{array}{l}\text { 11-Deoxy- Cortisol } \\
\text { cortisol }\end{array}$ & $\begin{array}{l}\text { 4-Andro- } \\
\text { stenedione }\end{array}$ & $\begin{array}{l}\text { 21-Deoxy- } \\
\text { cortisol }\end{array}$ \\
\hline $\begin{array}{l}\text { Range } \\
(\text { 1st-99th }\end{array}$ & & & & & \\
percentile) $<1.0-25$ & $<1.0-43$ & $10-1,786$ & $<1.0-21$ & $<1.0-4.7$ \\
\hline Patient 1 & 13 & 525 & 11 & 40 & 0.9 \\
Patient 2 & 15 & 665 & 31 & 51 & 3.1 \\
Patient 3 & 7 & 1,294 & 20 & 240 & 2.8 \\
Patient 4 & 4 & 472 & 20 & 63 & 2.3 \\
Patient 5 & 6 & 1,128 & 7 & 150 & 1.3 \\
\hline
\end{tabular}

Row 1: percentiles calculated for 597 newborns gestational age $>36$ weeks. Rows 2-6: steroid spectra of patients with 11-OHD, results of first second-tier test. Values are given in $\mathrm{nmol} / \mathrm{l}$.

\section{Results}

\section{Screening}

In a total of 6,359 samples analyzed by LC-MS/MS, 5 newborns were identified as suffering from 11-OHD (1 case in about 200,000 newborns) in addition to 78 cases of 21-OHD (1.2\% of second-tier tests). 11-Deoxycortisol was significantly elevated as depicted in table 1 . Levels of 4 -androstenedione were also clearly increased. As expected, the concentrations of cortisol were low. Values for 17-OHP and 21-deoxycortisol, which are the pathognomonic markers for 21-OHD, were within the normal range.

\section{Patients}

Patient 1: The male patient (karyotype 46,XY) was born in the 38th week of gestation to healthy parents of Turkish origin, who are first-degree cousins. His birth was unremarkable with a weight of $3,120 \mathrm{~g}(-1.05$ SDS), length $50 \mathrm{~cm}(-0.38$ SDS), Apgar 9/10, normal male genitalia with palpable scrotal-positioned gonads. The newborn screening sample was taken $36 \mathrm{~h}$ after birth; hydrocortisone substitution was started at the 10th day of life with a dose of $15 \mathrm{mg} / \mathrm{m}^{2}$. The boy did not show arterial hypertension or electrolyte disturbances at any point of time. His sister, who is 3 years older, showed ambiguous genitalia (Prader genital stage 3) at birth and was diagnosed with 11-OHD at the age of 14 months.

Patient 2: The boy was delivered by cesarean section at a gestational age of 39 weeks, birth weight $2,925 \mathrm{~g}(-1.13$ SDS), Apgar 9/10/10. He is the first child of healthy unre- 
Table 2. Follow-up data of patients $2-5$, no follow-up data available for patient 1

\begin{tabular}{llllllllr}
\hline Patient & $\begin{array}{l}\text { Age } \\
\text { months }\end{array}$ & Weight kg & BMI & $\begin{array}{l}\text { BMI- } \\
\text { SDS }\end{array}$ & $\begin{array}{l}\text { Height } \\
\mathrm{cm}\end{array}$ & $\begin{array}{l}\text { Height } \\
\text { SDS }\end{array}$ & $\begin{array}{l}\text { 11-Deoxycortisol } \\
\text { nmol/l (reference range) }\end{array}$ & $\begin{array}{l}\text { Hydrocortisone } \\
\text { mg/m } \text { body surface }^{-}\end{array}$ \\
\hline 2 & 40 & 17.5 & 17.2 & +1.2 & 101 & 0 & $0.21(0.3-4.0)$ & 21.0 \\
3 & 29 & 12.2 & 16.0 & -0.2 & 90 & -1.3 & $1.26(0.3-4.0)$ & 8.0 \\
4 & 19 & 10.2 & 15.9 & -0.8 & 80 & -1.0 & $0.42(0.3-3.7)$ & 12.5 \\
5 & 9 & 16.3 & 30.2 & +5.2 & 73.5 & -0.7 & $13.8(0.3-7.8)$ & 10.4 \\
\hline
\end{tabular}

lated parents of German descent. The child was hypotonic and hypoglycemic at birth. No malformations, normal male genitalia, testes descended. Blood collection for screening was done on day 3 of life. After confirmation of the diagnosis by a steroid profile done after ACTH stimulation, hydrocortisone therapy was started at the 11th day of life with $18 \mathrm{mg} / \mathrm{m}^{2}$. Postnatal development was unremarkable. Neither hypertension nor electrolyte disturbances were observed.

Patient 3: The boy is the first child of healthy consanguineous parents of German descent. After an uneventful pregnancy he was delivered by cesarean section because of suspected intrauterine infection in the 41st week of gestation, weight at birth was 4,570 $\mathrm{g}(+1.85$ SDS), Apgar $9 / 10 / 10$. The physical examination showed normal male genitalia, testes were palpable in the scrotum. The karyotype was male (46,XY). Blood collection for screening was done on day 3 of life. Treatment with hydrocortisone was started at day 9 after birth with a dose of 17 $\mathrm{mg} / \mathrm{m}^{2}$. Postnatal development was normal. The patient suffers from atopic dermatitis which is treated with topic steroids and moisturizers.

Patient 4: The girl (karyotype 46,XX) was born without complications after an uneventful pregnancy of 40 weeks. Birth weight: $3,600 \mathrm{~g}$ (+0.35 SDS), length $54 \mathrm{~cm}$ (+2.31 SDS), Apgar 9/10/10. The unrelated parents are of German descent. Virilization corresponded to Prader stage 3. Ultrasound examination showed female internal genitalia, adrenal glands were slightly hypertrophic. Blood collection for neonatal screening was done on day 3 of life. Therapy with hydrocortisone $\left(15 \mathrm{mg} / \mathrm{m}^{2}\right)$ started on the 7th day leading to normalization of 11-deoxycortisol levels within 8 weeks.

Patient 5: The girl is the third child of healthy nonconsanguineous parents. Her 2 older brothers are healthy. During pregnancy, ultrasound investigations demonstrated a suspicious genital anatomy. Amniocentesis was performed in the 16th week of gestation and yielded a normal result. The karyotype was female
$46, \mathrm{XX}$. The girl was delivered spontaneously in the 39th week of gestation, weight at birth $3,750 \mathrm{~g}(+1.03 \mathrm{SDS})$, length $53.5 \mathrm{~cm}(+2.26$ SDS), Apgar 6/9/10. The physical examination showed virilized external genitalia corresponding to Prader stage 5, testes were not palpable. Ultrasound investigation showed normal female internal genitalia, adrenal glands were both hyperplastic. Blood collection for screening was done on day 2 of life. Treatment with hydrocortisone was started immediately at a dose of $15 \mathrm{mg} / \mathrm{m}^{2}$. Postnatal development was normal. At the age of 9 months, a phallus reduction, urethral plastic and reconstruction of the introitus of the vagina was performed.

The first 4 patients were identified because of a moderately elevated concentration of 17-OHP in the immunoassay requiring a second-tier test. Patient 5 did not present with a positive screening test in the first sample but was detected because of ambiguous genitalia. The maternity unit had asked for a diagnostic steroid profile in addition to the standard screening program. Analysis of a second sample by immunoassay in this patient on the fourth day of life showed an elevated 17-OHP level. In 3 other patients, who were retested by immunoassay, 17OHP values were below the threshold. All patients showed elevated 11-deoxycortisol levels and low cortisol levels (table 1) detected either by RIA or LC-MS/MS techniques in confirmatory tests. Follow-up data of 4 patients are summarized in table 2 ; for patient 1 no further data were available.

\section{Molecular Analysis}

Patient 1: A homozygous point mutation c.348G>C; p.W116C in the CYP11B1 gene was found. The older sister and the parents were studied earlier. The parents were both heterozygous for the mutations. The mutation is causing the exchange p.W116C in the P450C11 protein, abolishing its activity as previously shown [4].

Patient 2: Molecular analysis of the CYP11B1 gene did not reveal any disease causing variation within the cod- 
ing exons and the exon-intron boundaries. The genetic basis of the defect is still unknown. It may be possible that intronic variations or mutations in the promoter region which were not completely sequenced are responsible for the inactivation of the protein or RNA transcription, respectively.

Patient 3: The boy is carrying a homozygous point mutation c.346T>G; p.W116G leading to an amino acid exchange at the same codon as patient 1 . Tryptophan 116 is mutated to glycine. As the mutation of the residue 116 to cysteine is abolishing P450C11 activity, it is likely that the exchange to glycine is also inactivating the protein.

Patient 4: The DNA was not investigated as the parents did not give their consent to the analysis.

Patient 5: A novel splice site mutation in intron 4 (IVS4+2T >C) was detected for which both parents are heterozygous. It is therefore highly likely that the P450C11 protein is inactivated due to aberrant splicing.

\section{Discussion}

Newborn screening for CAH has been improved considerably by the introduction of second-tier analysis by LC-MS/MS [2, 3, 6-9]. With significantly reduced analytical time [10], this technique will probably be used more frequently. It does not only help to reduce the proportion of false-positive results in 21-OHD, but it also allows identification of newborns suffering from 11-OHD when 11-deoxycortisol is included in the steroid profile. As long as CAH screening is performed by immunoassay, the detection of this variety, however, depends on positive results of the primary test.

Since hydroxylation of 11-deoxycortisol to cortisol is blocked in patients with 11-OHD, it is obvious that high concentrations of 11-deoxycortisol in the presence of low cortisol levels are the biochemical hallmarks of this variation of CAH. 4-Androstenedione reflecting the increased activity of the hypothalamic-pituitary axis is also expected to accumulate, which could be shown in the cases detected here. It has also been described that concentrations of 17-OHP as a metabolite further upstream were elevated in affected infants [11]. Thus, it seemed reasonable to expect positive results in the immunological screening test for 17-OHP. This has indeed repeatedly been found. In the LC-MS/MS steroid profiles, however, 17-OHP did not exceed normal concentrations in the 11OHD patients examined here. This was not only true for the first profile but also for the second sample taken before treatment started.
Cross-reactivity of the antibody with steroids other than 17-OHP seems to be the reason for moderately elevated test results in immunological assays used for newborn screening. In this particular situation, lack of antibody specificity was of advantage for the patients diagnosed. Unspecific reactivity of the antibody in the test kit used was not marked enough, however, to yield positive results in all examinations. Each of the 4 patients tested twice within a few days after birth tested negative for 17-OHP in the immunoassay. Krone et al. [4] described a boy with 11-OHD detected on clinical grounds. The original screening test had been negative for CAH. A repeat blood spot test 4 weeks later, however, resulted in a marginally elevated $17-\mathrm{OHP}$ value. With the immunoassay used in our laboratory, some patients with 11-OHD may not have been detected. The 5 cases found here will most probably not represent the total prevalence of the genetic defect in our series of nearly a million newborns. The true incidence of 11$\mathrm{OHD}$ in Europe is not exactly known. It has been estimated to account for up to $10 \%$ of all cases of CAH [11]. The number of cases which we detected corresponds to this order of magnitude.

11-OHD was initially described as the hypertensive form of CAH [12] since elevated blood pressure is observed in a high percentage of affected infants. Without early and sufficient treatment, left ventricular hypertrophy will occur. Such patients are at risk of retinopathy and death from cerebrovascular apoplexy. Early somatic growth and rapid bone age advancement as well as premature adrenarche and pseudo-precocious puberty occur in both sexes. Final height is severely compromised in untreated patients. Males may develop precocious onset of central puberty. In females with normal genitalia at birth, virilization is sometimes only observed in childhood or adolescence. Although 11-OHD is a rare disease, it is an important health problem. The natural history of the disease is well understood. An accepted treatment exists and facilities for diagnosis and treatment are available. Using the method described here the disease can be identified at an early stage. The costs of finding cases of $11-\mathrm{OHD}$ in addition to 21-OHD are very low. Thus, the main criteria for screening as described by Wilson and Jungner [13] are fulfilled for 11-OHD. 11-OHD should therefore become a target disease of routine newborn screening. 


\section{Acknowledgements}

We are grateful to Michael Terhardt, Martina Nega and Sarah Korsch for their helpful technical assistance.

\section{Disclosure Statement}

All authors declare that there is no conflict of interest that could be perceived as prejudicing the impartiality of the research reported.

\section{References}

1 Lee JE, Moon Y, Lee MH, Jun YH, Oh KI, Choi JW: Corrected $17 \alpha$-hydroxyprogesterone values adjusted by a scoring system for screening congenital adrenal hyperplasia in premature infants. Ann Clin Lab Sci 2008; 38:235-240.

2 Janzen N, Peter M, Sander S, Steuerwald U, Terhardt M, Holtkamp U, Sander J: Newborn screening for congenital adrenal hyperplasia: additional steroid profile using liquid chromatography-tandem mass spectrometry. J Clin Endocrinol Metab 2007;92:25812589.

- 3 Janzen N, Sander S, Terhardt M, Peter M, Sander J: Fast and direct quantification of adrenal steroids by tandem mass spectrometry in serum and dried blood spots. J Chromatogr B Analyt Technol Biomed Life Sci 2008;861:117-122.
4 Krone N, Riepe FG, Gotze D, Korsch E, Rister M, Commentz J, Partsch CJ, Grotzinger J, Peter M, Sippell WG: Congenital adrenal hyperplasia due to 11-hydroxylase deficiency: functional characterization of two novel point mutations and a three-base pair deletion in the CYP11B1 gene. J Clin Endocrinol Metab 2005;90:3724-3730.

-5 Antonarakis SE: Recommendations for a nomenclature system for human gene mutations. Nomenclature Working Group. Hum Mutat 1998;11:1-3.

-6 Schwarz E, Liu A, Randall H, Haslip C, Keune F, Murray M, Longo N, Pasquali M: Use of steroid profiling by UPLC-MS/MS as a second-tier test in newborn screening for congenital adrenal hyperplasia: the Utah experience. Pediatr Res 2009;66:230-235.

$\checkmark 7$ De Jesus VR, Simms DA, Schiffer J, Kennedy M, Mei JV, Hannon WH: Pilot proficiency testing study for second tier congenital adrenal hyperplasia newborn screening. Clin Chim Acta 2010;411:1684-1687.

8 Rauh M: Steroid measurement with LC-MS/ MS in pediatric endocrinology. Mol Cell Endocrinol 2009;301:272-281.
9 Honda A, Yamashita K, Miyazaki H, Shirai M, Ikegami T, Xu G, Numazawa M, Hara T, Matsuzaki Y: Highly sensitive analysis of sterol profiles in human serum by LC-ESI-MS/ MS. J Lipid Res 2008;49:2063-2073.

10 Janzen N, Sander S, Terhardt M, Steuerwald U, Peter M, Das AM, Sander J: Rapid steroid hormone quantification for congenital adrenal hyperplasia in dried blood spots using UPLC liquid chromatography-tandem mass spectrometry. Steroids 2011;76:1437-1442.

11 Nimkarn S, New MI: Steroid 11 $\beta$-hydroxylase deficiency congenital adrenal hyperplasia. Trends Endocrinol Metab 2008;19:9699.

12 Bongiovanni AM, Eberlein WR: Plasma and urinary corticosteroids in the hypertensive form of congenital adrenal hyperplasia. J Biol Chem 1956;223:85-94.

13 Wilson JM, Jungner YG: Principles and Practice of Mass Screening for Disease. Geneva, WHO, 1968 (http://www.who.int/bulletin/volumes/86/4/07-050112BP.pdf). 